is that by the end of 1963 some 250 million persons had been vaccinated with them and even in vaccinated communities harbouring residual strains of wild virus the " maximum potential risk rate" was about 1.04 cases per million persons vaccinated. If infection with wild virus is eliminated the safety of Sabin oral poliovaccine has been claimed by P. F. Wehrle and his colleagues ${ }^{6}$ to be even higher-" no vaccineassociated illness following 7.5 million doses." Such, then, is the order of safety for both types of vaccine against which another, newly recognized risk must be viewed.

Until recently virtually all attention to the risks of poliovaccines has been focused on possible direct infection of the nervous system with living virus capable of causing paralytic disease. Sabin ${ }^{4}$ has pointed out that in recent years certain Coxsackie A, Coxsackie B, Echo, and even mumps viruses have been proved to cause paralytic illness clinically indistinguishable from poliomyelitis. But apart from this risk, and apart from sporadic infection with wild strains of true polio virus within the community, a risk is now recognized of neuroparalytic.accidents of polyradiculoneuritis type, with or without damage to the spinal cord (Landry or GuillainBarré syndromes). ${ }^{7-10}$ In all cases these neurological complications have been a sequel to oral poliovaccines. S. Bojinov and his colleagues ${ }^{9}$ describe in detail the histories and neurological signs of their 13 patients ; two were adults and the rest children under 9 years old. Twelve recovered, but the sole fatal case showed histological signs of a meningomyeloradiculitis, with fibrinoid changes in the walls of small blood-vessels in the medulla and spinal cord. These neuroparalytic accidents, as it seems permissible to call them, occurred two to twenty-usually about seven-days after poliovaccination, and seem to have been indistinguishable from the classical neuroallergic complications of vaccinia or anti-rabies inoculation. No Coxsackie or wild strains of poliovirus were isolated.

Since these 13 cases occurred out of about 6 million persons given oral vaccine the risk, as the Bulgarian authors say, is so small that the prophylactic value of the vaccine is not to be questioned. Nevertheless their report is important, along with that of G. Bodechtel and his co-workers, ${ }^{10}$ in showing that poliovaccination is yet another agent that may provoke a neuroallergic type of reaction. Sabin himself ${ }^{4}$ has mentioned that " one of the two patients reported from Michigan this year as having died of poliomyelitis within an interval of 16 days after Salk vaccine (our italics) was found on autopsy to have a disseminated myelitis. A fatal, poliomyelitis-like paralytic illness, without sensory signs, in a man who had received Type III oral vaccine . . . also turned out to be a case of disseminated encephalomyelitis without any demonstrable virus in the central nervous system or stools." Hence it is likely that such complications are not related to the viability of the virus in the vaccine, and that risks of a neuroallergic reaction are probably equal with both the Salk and

\footnotetext{
1. Brit. med. F., 1955, 1, 1144, 1166.

Ibid., 1958, i, 349.

- Geffen, D. H., In Proceedings of Symposium on Immunization in Childhood, edited by D. A. Cannon et al., p. 23, 1960. Edinburgh and London, E. and S. Livingstone.

Sabin, A. B., F. Amer. med. Ass., 1963, 183, 268.

Brit. med. F., 1963, 2, 731

Fehrle, P. F., Leedom, J. M., Portnoy, B., Pierce, N. F., and Cowper, H. H., F. Amer med. Ass., 1963, 186, 821

Pattinson, G. N., Brit. med. F., 1963, 2, 116.

8 Russell, W. R., ibid., 1963, 2, 178.

- Bojinov, S., Kirov, I., Georgiev, I., Mitov, G., Kohen, M., Ninov, N., Savov, Z., and Kaneva, J., Presse mód., 1964, 72, 75.

Bodechtel, G., Haas, R., Joppich, G., Lennartz, H., Pette, H., and Siegert, R., Germ. méd. Mth., 1964, o, 1.

1* Wynne-Griffith, G., Proceedings of Sympositum on Immunization in Childhood, edited by D. A. Cannon et al., p. 29, 1960. Edinburgh and London, E. and S. Livingstone.
}

Sabin types of vaccine. Further, their incidence is probably about the same, or even less, than those of disseminated encephalomyelitis after vaccination against smallpox. ${ }^{11}$ Such complications emphasize the urgency of the need to solve the nature of the cause of " neuroallergy."

\section{Cancer Registration}

Cancer registration in England and Wales began as an offshoot of radiotherapy. In the early days supplies of radium were controlled by the Government, and radiotherapeutic departments were required to keep records of the patients treated with radium. It was a natural step to extend these records to all patients undergoing radiotherapy.

Since the introduction of the National Health Service there has been a gradual spread of the practice of registering all patients suffering from cancer. This is done on a regional basis, and the records are used locally for clinical and administrative purposes. Many regions publish analyses of their experience in the form of annual reports, and last year the Ministry of Health held a conference on the subject. ${ }^{1}$

In addition to the regional registries there is a central organization at the General Register Office which co-ordinates the local records and helps to eliminate the collection of duplicate records for the same patient in different regions. The General Register Office also supplies the regional offices with death certificates of patients certified as dying of cancer to provide some information on the completeness of registration and to provide a check on cancer cases which were never treated at a hospital.

From time to time analyses of the statistics have been published by the General Register Office. The basic purpose of cancer registration in England and Wales is to get information on the incidence of cancer and the survival of patients. It also gives a local service for following up the patients to ensure adequate treatment and to keep surgeons informed of progress. Mortality records alone, which have so far been the main source of information, do not give a true picture of the incidence of different types of cancer or of the prevalence of cases in the community. This can be provided only by registration or notification. In addition to this the facilities and records of the organization provide opportunities for special studies and investigations in the epidemiology of cancer. The possibilities of the scheme in this respect have as yet been hardly touched, but there is little doubt of their potential value, particularly if information collected can be varied according to needs.

One of the earliest suggestions for the use of cancer registration was to compare the value of different forms of treatment. Since then the development of the clinical trial and experience of the many pitfalls of uncontrolled comparisons of treatment have cast doubt on this use of it. However, clinical trials done by particularly skilled surgeons in a favourable environment are not necessarily indicative of the results of treatment under normal working conditions. The only source of information on this for some time is likely to be provided by cancer registration.

At present it is estimated that registration covers about $70-80 \%$ of the cases of cancer in the country, but there are wide variations in completeness, some regions covering $90 \%$

1 Brit. med. F., 1963, 1, 422. 
or more cases, others far less. The success of the scheme and its benefits depend on local interest and co-operation, and it is to be hoped that, as the benefits come to be more generally realized, virtually $100 \%$ registration will be achieved in the next few years.

\section{Inherited Disorders of Potassium Metabolism}

Familial periodic paralysis ${ }^{1}$ and adynamia episodica hereditaria ${ }^{2-6}$ are inherited disorders of potassium metabolism which present clinically with spontaneous transient flaccid paralyses or pareses. Despite their similarities, however, the former is associated with a reduced concentration of potassium in the blood, ${ }^{7}$ while in the latter this is normal or raised. The occurrence of clinically similar attacks was recognized before the relationship to potassium metabolism was appreciated. ${ }^{8}$

The symptoms of familial periodic paralysis usually begin in the second decade of life and may become less severe in old age. Attacks usually begin at night and mainly affect the limbs and trunk, sparing the facial, diaphragmatic, pharyngeal, and laryngeal muscles. Tendon reflexes and the response of the affected muscles to electrical stimulation are lost in the attacks. Recovery is often preceded by diuresis and sweating, while the muscles recover their function in the reverse order from that in which the paralysis developed. The frequency of the attacks is very variable, but the patient is completely free of symptoms between them. Potassium moves into the cells at the beginning of an attack of paralysis, and the serum-potassium concentration, which is normal or low between attacks, decreases rapidly. The potassium content of skeletal muscle increases, while its sodium content does not change. The total exchangeable potassium of the body is low while that of sodium is somewhat increased: a glucosetolerance test may show an apparent increase in tolerance. ${ }^{9}$ Attacks may be precipitated by changing the sodium balance in either direction, ${ }^{10}$ heavy exercise, ${ }^{11}$ a heavy meal, or administering glucose, insulin, adrenocortical steroids, or corticotrophin. Potassium salts by mouth, restriction of the intake of sodium, and the administration of a thiazide diuretic or spironolactone may be of help in treatment.

Familial periodic paralysis is transmitted as an autosomal dominant, though penetrance of the gene is sometimes incomplete, men tending to show more severe clinical manifestations than women; the disease is fatal in about $10 \%$ of patients. The cause of the attacks is unknown, though some have suggested that a primary disorder of the hypothalamus with intermittent excessive secretion of aldosterone or that a primary defect of the permeability of muscle membranes is responsible.

Spontaneous attacks of flaccid paresis or paralysis begin during the first decade of life in adynamia episodica hereditaria and are usually less severe than those in familial periodic paralysis. During the attacks the level of potassium in the serum is raised or normal, and the concentration of potassium in the urine is not decreased. The disease is inherited as an autosomal dominant trait with complete or almost complete penetrance, and affected families sometimes have a history of migraine. Potassium metabolism appears to be normal between the attacks, which can be precipitated by the ingestion of potassium salts, during rest after severe muscular exertion, or by emotional stress or hunger. If glucose is given before the potassium salts it inhibits their action, while J. Gamstorp and his colleagues found that the intravenous injection of calcium gluconate curtailed the attacks. ${ }^{6}$ Treatment with an agent that inhibits carbonic anhydrase or with a thiazide diuretic to produce a loss of potassium in the urine has also given promising results. ${ }^{12}$ Though glucose or a meal may ward off an attack, both these measures or the injection of insulin may actually precipitate one after an interval of several hours.

In reporting four patients with adynamia episodica hereditaria R. H. Herman and M. K. McDowell ${ }^{13}$ found that giving glucose in an attack lowered the serum-potassium level, produced E.C.G. changes (depression of the ST segments and $T$ waves), and diminished the muscle weakness. All their patients were improved clinically by $20-40 \mathrm{~g}$. glucose four or five times daily by mouth. They suggest that the basic defect is in the transport of potassium across the muscle-cell membrane in both directions, and that potassium ions accumulate at the cell boundary. H. G. Mertens and his colleagues $^{14}$ found that depleting their patient of sodium, or blocking the production of aldosterone, increased the severity of the attacks of paralysis, while giving sodium chloride or aldosterone improved them.

Though myotonia has not been generally recognized in adynamia periodica hereditaria McArdle, ${ }^{12}$ Herman and McDowell, ${ }^{13}$ and Mertens and his co-workers ${ }^{14}$ all described patients in whom this was a feature. Furthermore, J. P. van der Meulen and his colleagues ${ }^{15}$ reported a condition which they called "familial hyperkalaemic paralysis with myotonia," in which the attacks of paralysis were abolished by an intravenous injection of hydrochlorothiazide. Myotonia is usually mild and may be demonstrable only in selected muscles (e.g., as a myotonic lid-lag or in the tongue). Further studies are needed to determine if it is a constant feature of adynamia periodica hereditaria or if cases with this manifestation belong to a different nosological entity. Myotonia is occasionally seen in other disorders of muscle, such as polymyositis" ${ }^{16}$ or the syndrome of "familial myotonic periodic paralysis" described by W. van't Hoff. ${ }^{17}$ Clearly there is still considerable doubt about the inter-relationship of various disorders of muscle, and it is to be hoped that all cases will be carefully examined for minor degrees of myotonia and fully investigated biochemically to resolve some of these difficulties.

${ }^{1}$ McArdle, B., Brit. med. Bull., 1956, $12,226$.

" Conn, J. W., and Streeton, D. H. P., in Metabolic Basis of Inherited Disease, ed. J. B. Stanbury, J. B. Wyngaarden, and D. S. Fredrickson, 1960. London, McGraw-Hill.

${ }^{3}$ Tyler, F. H., Stephens, F. E., Gunn, F. D., and Perkoff, G. T., Y. clin. Invest., 1951, 30, 492.

${ }^{4}$ Gamstorp, I., Acta Paediat. (Uppsala), 1956, 45, Suppl. No. 108.

5 - Acta genet. (Basel), 1957, 7, 325.

- Hauge, M., Helweg-Larsen, H. F., Mjönes, H., and Sagil, d. U., Amer. F. Med., 1957, 23, 385.

' Aitken, R. S., Allott, E. N., Castleden, L. I. M., and Walker, M., Clin. Sci., 1937, 3, 47.

${ }^{8}$ Idelson, V., Lond. med. Record., 1884, 12, 130.

${ }^{9}$ MacGregor, G. A., and Shaper, A. G., Brit. med. F., 1957, 1, 917.

${ }^{10}$ Doak, P. B., and Eyre, K. E. D., ibid., 1961, 2, 549.

11 Soyse, E.,; ibid., 1949, 2, 470.

${ }^{12}$ McArdle, B., Brain, 1962, 85, 121.

${ }^{13}$ Herman, R. H., and McDowell, M. K., Amer. F. Med., 1963, 35, 749.

${ }^{14}$ Mertens, H. G., Schimrigk, K., Volkwein, U., ard Voigt, K. D., Klin. Wschr., 1964, 42, 65.

${ }^{15}$ Van der Meulen, J. P., Gilbert, G. J., and Kane, C. A., New Engl. Y. Med., $1961,264,1$.

${ }_{16}$ Walton, J. N., and Adams, R. D., Polymyositis, 1958. Edinburgh and London, Livingstone.

17 Van't Hoff, W., Quart. F. Med., 1962, 31, 385. 